\title{
MECHANIZATION AND THE FOREST INDUSTRY (EASTERN CANADA AND SOUTHEASTERN UNITED STATES) ${ }^{1}$
}

\author{
By G. E. QUAILE ${ }^{2}$
}

\section{INTRODUCTION}

Mechanization of the harvesting process in Eastern Canada has made great strides in the recent past as is evidenced by the machines in use on the limits of Great Lakes Paper and Abitibi Power and Paper Companies. Such progress does not come easily or without great developmental expense, and the pulp and paper industry along with many equipment manufacturers should be pleased with a job well done. To observe these operations is an awesome experience, particularly if one's imagination permits the realization that these machines are seen through hardly more than a crack in the door to the future.

Like many of you I have frequently asked myself why mechanization has taken so long to gain this solid foothold in our timber industry when other industries appear to be so advanced technologically. I venture the opinion that only an abundance of relatively low cost labor has permitted us to continue competitively. It is axiomatic in our competitive economy that mechanization per se will not succeed without an economic need.

As labor rates in Eastern Canada increased along with camp overhead and other associated costs, opportunities for employing machines and eliminating men began to expand. Human inventiveness moved rapidly to supply the answers. Furthermore, as wages and payroll expense continue to climb rapidly a proliferation of mechanical innovations can be expected for economically replacing men.

Until last year the Southeast enjoyed an abundance of relatively low cost commutor labor in the timber industry. The change, when it began to take place, differed from the Canadian experience. Instead of being confronted with excessive wage rates and associated overhead, a decreasing trend in the availability of labor was recognized which was, within practical limits, inelastic to demand. A general shift of population from rural to urban areas was and is still occurring. Of those that remain many are unwilling at any practical price to undertake the arduous work required in present forest product harvesting techniques. Others will work, but, as soon as their weekly income demands are met, they have no further incentive to continue working until the following week.

As a result considerable difficulty is being experienced by the pulp and paper industry, in the Southeast, in developing economic justification for capital intensive systems. These must meet competition from existing labor

\footnotetext{
A viewpoint presented following the field trips of the 1965 Annual Meeting of the C.I.F.

- Wese Virginia Pulp and Paper Co. Led., New York, U.S.A.
} 
intensive systems still enjoying low labor rates (when labor is available). In general, those companies who are equipping for mechanized logging are doing so in the realization that the only alternative is to experience reduced wood supplies due not to a lack of resource but to a lack of labor. This is unattractive in the face of expanding paper markets.

\section{Forest MANagement and Mechanization}

The problem before us is to assess the adjustments required in the relationship of forest management and mechanized harvesting. I suspect that these essentially will be in form of reactions on the part of forest management since activities in this functional area are dependent upon operating margins developed through stumpage, and stumpage must be considered a residual.

In eastern Canada, due to the high costs of limit development and logging, the operating margin for forest management is minimal, necessitating an extensive approach to forest management.

As areas develop merchantable stumpage for a second crop these developmental costs will not be as high, and larger operating margins will result, permitting more intensive management.

Since the Southeast is a well developed region from the standpoint of the forest resource it perhaps will be interesting to describe for you my estimate of the reaction of forest management to mechanized harvesting. Because the Southeast is well developed, stumpage is high, permitting substantial operating margins for forest management. Furthermore, the stumpage market is far more competitive than the monopolistic crown limit situation in Canada, and this further tends to bolster high stumpage prices.

Increasing competition for the available resource is forcing the pulp and paper industry into direct competition with sawmills for small-and mediumsized sawtimber. While this trend has tended to increase the delivered cost per unit of volume when stumpage is included, two factors now give hope of maintaining an acceptable cost per o.d. ton of pulp. The first is the strong indication gathered from our research as well as from others that fibre yield from sawlog portions of trees is superior to that obtained from our more conventional types of roundwood furnish. Secondly, the productivity of mechanized logging responds favorably to increasing tree size, and the resulting lower operating costs in stands of larger diameter trees will offset most, if not all, of the higher stumpage rates.

The effect of this will be to change management objectives which historically have been related to the growth of products suitable for the so-called quality markets. With the pulp industry competing for this material tonnage growth will become a prime objective, and existing concepts of financial maturity will be altered accordingly. The result could well be a reduction in the length of stand rotation. A lower age limit, however, for stand rotation will likely result from the sensitivity which capital intensive harvesting systems thus far exhibit towards the variable of tree size. Any reduction of rotation cycles which would yield an average tree size below the optimum operational range for these systems will be resisted by rapidly decreasing stumpage rates.

A major problem faced by the Southeast as the area advances into the 
mechanical age is that of thinning. Without this silvicultural technique individual tree growth rates are substantially reduced. Thinnings have been economically attractive in large measure because of the high stumpage rates which have resulted from the fact that labor intensive systems are relatively insensitive to tree size. It is reasonably certain, however, that such systems will soon be of the past, having been replaced by capital intensive systems which to date have been unable to cope economically with small trees.

Therefore, it appears to me that only two courses of action are open. First of all, mechanized logging systems must be developed which can handle small stems. At the same time and in recognition of the difficulty in achieving this latter objective, forest managers must be searching for ways to decrease their heavy dependence on thinning as a silvicultural technique. Failing success in either of these approaches, I see no alternative other than perhaps what might be termed mechanical elimination to obtain the effect of thinning.

\section{CONCLUSION}

In attempting to draw some parallels from Southeastern experience for the Canadian future it is first necessary to determine what are the economic factors against which this future will unfold. One of the most rewarding experiences I have had was a recent trip to the Northwest. A tour was made one day north of Seattle to Everett in the Willamette Valley and then eastward up into the Cascades. Before leaving the Valley a number of young stands were passed, but no old growth. But most surprising to me was to find logging proceeding in these young stands where the resulting logs were no larger and frequently smaller than those in Southeast, and far smaller than those being produced a scant twenty miles up into the mountains. This is the effect of previous logging development on today's timber management. Rotation age is inversely related to accessibility.

The second crop in Canada will probably be affected in the same manner, and this certainly would indicate tree sizes no larger than those being experienced presently. I would have said that smaller diameters would result except that I cannot visualize any smaller timber than that which already exists being economically practical for mechanical harvesting. The forest manager's problem will again be to achieve an economic tree size rapidly with a minimal reliance on thinning.

There are other problems as the machine age is entered, but none, in my estimation, are as pressing as that of what to do about the small tree. The fibre potential in this size class is tremendous, particularly in areas of tight supply. When this situation will develop in Canada 1 do not know. My hope is that when it does better prospects for an economic solution will be available than are in existence today for the Southeast. 